This is a post-peer-review, version of an article published in Business Process Management Journal (Vol. 24 No. 3, 2018 pp. 786-813) The final version is available on Emerald Insight at: http://dx.doi.org/10.1108/BPMJ-11-2016-0226. This version of an article is distributed under the terms of the Creative Commons Attribution Non-commercial International Licence 4.0 (CC BY-NC 4.0)

\title{
BUSINESS PROCESS MANAGEMENT - AT THE CROSSROADS
}

Monika Klun, University of Ljubljana - Faculty of Economics, monika.klun@ef.uni-lj.si Peter Trkman, University of Ljubljana - Faculty of Economics, peter.trkman@ef.uni-lj.si

\begin{abstract}
.
Purpose Business process management (BPM) has received much focus throughout the years, yet there have been calls questioning the future of BPM. This paper aims to explore the current state of the field through a dynamic literature review and identify the main challenges for its future development.
\end{abstract}

Design/methodology/approach A dynamic co-citation network analysis identifies the "evolution" of knowledge of BPM and the most influencing works. The results present the developed subthemes of BPM in the form of clusters.

Findings The focus within the field has shifted from facilitating wide-ranging business performance improvements to creating introverted optimizations within a particular BPM subgroup. The BPM field has thus experienced strong fragmentation throughout the years and has accrued into self-fueling subareas of BPM research such as business process modeling and workflow management. Those subareas often neglect related disciplines in other management, process modeling, and organizational improvement fields.

Research limitations/implications The study is limited by the initial keyword choice of the authors. The subsequent co-citation analysis ameliorates the subjectivity since it produces a dataset of papers and contributions based on references.

Originality/value A new combination of historical development and state-of-the-art of the BPM field, by employing a co-citation and cluster analysis. This dynamic literature review presents the current state of the theoretical core and attempts to identify the crossroads that BPM has reached. The study can be replicated in the future to the track the changes in the field.

Keywords Research progress, workflow, process modeling, success factors, co-citation analysis, cluster analysis

Paper Classification Literature review 


\section{Introduction}

Business process management (BPM) as a field can be understood as relatively old - the conceptual roots can be found stemming from several highly researched management concepts of the 20th century, like business process reengineering (BPR) and statistical process control (Rosemann, 2014, van der Aalst, 2012). Yet even though the take-up of BPM has been widespread many question not only the identity but also the quality and maturity of the BPM field (Recker and Mendling, 2016, van der Aalst, 2013b). Al-Mashari (2002) pointed to a sense of opacity and "mist" surrounding the term. Smart et al. (2009) referred to the "relative paucity" of the conceptual analyses and rigorous empirical research as a possible cause for the "confusion surrounding BPM." Recker (2014) expressed the need to clearly define and specify the essential concepts of BPM.

Nowadays a myriad of papers discussing BPM provide researchers with numbers of definitions; an example by vom Brocke and Rosemann (2010) of BPM being "[a] holistic management approach that focuses on aligning all aspects of an organization with the requirements of their customers, while still promoting business effectiveness and efficiency." An exceedingly general definition can also mean that BPM as a concept becomes an overly ambiguous affair (van der Aalst et al., 2003).

Such an overly extensive, "all-encompassing" definition runs the risk of not clearly delineating the BPM field. Different papers offer different definitions that add to the mist surrounding BPM (Chountalas, 2012). Without a clear and consistent understanding of what BPM is (and what it is not) there exists the predicament that almost anything can be construed as BPM since de facto every activity is a process or part of the process of some sort. Rosemann and vom Brocke (2015) introduced the six core elements of BPM in an attempt to clearly define what constitutes BPM. However that does not provide a sufficient enough answer to the question of what is the structure or composition of the research efforts in the BPM field.

Several authors, such as Sidorova and Isik (2010) and Møller et al. (2007) have emphasized the lack of a holistic and dynamic perspective of the scope of the field. Harmon (2010) presented a broad survey of the business process movement and accounts for the business process traditions that have created the platform for today`s BPM. Literature reviews concerning BPM, e.g. Møller et al. (2007) or Iritani et al. (2015) have contributed outlooks on BPM constitution, identifying sets of conceptual clusters. Similarly, (Anand et al., 2013) performed a literature review of BPM, BPR and business process innovation (BPI), however co-citation or cluster analyses.

Additionally, with the emersion of new concepts such as digital transformation, there has been considerable concern expressed about the future of BPM. Despite the development of the field, many companies have reported being unsatisfied with the results of BPM projects (vom Brocke, 2016). Is BPM under threat of becoming expendable and unappealing for both practice and research? One proposed culprit of such unsuccessful business improvements is an excessively narrow view of BPM (vom Brocke, 2016). Accordingly, we claim that a more comprehensive approach to identifying the BPM "market of ideas" is still missing to identify both the past development, current trends and to guide future development. In the hope of 
contributing to a clarification, this paper presents a rigorous analysis aimed at identifying the core concepts and themes that BPM currently represents.

The purpose of this paper is thus to explore the theoretical core of BPM. The paper addresses the following research questions: (1) How did the core knowledge of the BPM field evolve through time? (2) Which papers were the most influential within the BPM field? (3) Which are the prevailing themes within BPM? The paper uses both a co-citation analysis and a cluster analysis for a clear visual representation of the knowledge development and main subthemes combining the field of BPM. In addition to contributing to a clearer field delineation, additionally performed qualitative analyses bridge the gap between BPM and fields from neighboring, content-related disciplines.

The structure of the paper is as follows: beginning with the background, the paper presents the BPM research up to now, identifying the research gap and motivation for addressing it. The methodology section explains the way in which co-citation and cluster analysis were done. The following subsection shows the evolution of BPM followed by the presentation of 6 clusters and related disciplines, identifying the state-of-the-art of the BPM field. Finally, we summarize the outlook of the BPM field and future work.

\section{The BPM field}

As nicely summarized by Ramiller et al. (2008) the BPM field tends to create research agendas according to current "fashionable" approaches and hypes in the industry. In a recent analysis, van der Aalst (2013a) identified the papers presented at the BPM conference to be "reductionistic in scope" and presenting either highly popular issues or "exotic or even nonexisting problems."

BPM, as well as many similar fields like research on entrepreneurship (Schildt et al., 2006), can be characterized as diverse and fragmented since there is no widely accepted categorization of different streams and it is not even clear if and how many distinct streams exist. Several fields have encountered developmental stages when numerous calls for a clear center of the field ensued. One such field was the information systems (IS) field, which received one type of answer in the paper by Lyytinen and King (2004) discussing academic legitimacy in IS. Similarly, questions of identity have also been addressed to BPM, as well as the need to "discuss how BPM research can be further developed" (Mendling, 2016).

As BPM is understood to be a still-emerging field within the academic discipline of Information Systems (IS) (vom Brocke et al., 2011), issues regarding the legitimacy and core of IS can prove insightful also for BPM. Some years ago the field of IS had undergone serious debates regarding the establishment of legitimacy and core themes (or lack thereof). Several researchers claimed the lack of a clear theoretical core, resulting in the IS not having a strong shared identity. While some feared that exceeding diversity could dilute the field and cause its demise (Benbasat and Weber, 1996), others e.g. DeSanctis (2003), Robey (2003), Galliers (2003), Lyytinen and King (2006) highly valued diversity without "articulated boundaries". Among the later were also Lyytinen and King (2004) discussing if IS should have a live core of "fixed ideas or relationships". Dispelling the need for a delimited center or 
core of the field, Lyytinen and King favored a notion of a "market of ideas", where the thoughts and ideas are free to be traded with, producing a medley that will spawn future development and research precisely because of its unboundedness. The free-flowing market enables the discipline to expand through exchange of intellectual contributions. While no one true compromise has emerged from this debate, some general recommendations emerged e.g. Benbasat and Weber (1996) emphasized the need for both focusing on the core of the discipline as well as on achieving diversity of methods, topics and research. Similarly, Taylor et al. (2010) introduce the concept of a polycentric core that retains the field's diversity.

The field of BPM has also encountered some calls for differentiation and calls expressing a lack of rigorous theoretical foundations (Rosemann, 2006, vom Brocke et al., 2011). Schildt et al. (2006) emphasized that such lack of clear research trajectories can inhibit the growth of a discipline as a scholarly endeavor. Recker and Mendling (2016) agreed that as with other academic disciplines, the BPM field is also strewn with debates exploring both the identity and the quality of the field.

While many authors believe BPM to have evolved into a holistic field, e.g. Baumann et al. (2015), Rosemann and vom Brocke (2015), vom Brocke et al. (2015), the predominance of the technical aspects (i.e. process modeling, workflow optimization) remains apparent (Dumas et al., 2013, Gorbacheva et al., 2015, Schmiedel et al., 2014). However, critical success factors of BPM are usually identified as non-technical (Trkman, 2010) thus a narrow focus may make it more difficult to attract the attention of the business academic and practitioner community.

Despite appeals for a more holistic approach, most literature reviews within the field tackle a particular subcategory of BPM. vom Brocke and Sinnl (2011) provided a framework of concepts denoting culture in the BPM perspective. Kohlbacher (2010) explored studies on process orientation and its effects on organizational performance. Aldin and de Cesare (2011) focused on the reusability of business process models as one of the major problems of process model design while Moreno-Montes de Oca et al. (2015) systematically reviewed studies on business process modeling quality.

On the other hand, there are examples of papers exploring the field of BPM in a comprehensive manner. Zairi (1997) offered a holistic overview and proposes the set of rules for BPM in practice. Among the earlier literature review papers, Lee and Dale (1998) examined the principles, approaches, and definitions comprising BPM. A two-stage literature review by Møller et al. (2007) lexically analysed the concepts that best explain BPM, concluding that overwhelmingly BPM is a "practically oriented concept with a weak academic foundation". Each of the resulting concepts (Management, Technology, Support, and Approach) is discussed in relation to BPM as an overlaying concept. Sidorova and Isik (2010) defined the business process core and associated themes, based upon a cross-disciplinary literature review. Iritani et al. (2015) provided a bibliometric analysis of the field, yet without an evolutionary portrayal of key concepts. These are provided in our paper along with the identification of the primary research directions.

Thus, there have been several literature reviews that attempted to produce conceptual frameworks and conceptual clusters forming BPM, yet none that would provide a map of the de- 
velopment of the scientific field and "significant intellectual connections within the field" (see e.g. (Grover et al., 2006, Small, 1973).

\section{Methodology}

We attempt to answer the research questions stated in the introduction by applying quantitative literature review using the bibliometric techniques of citation and co-citation analysis, additionally triangulated by a traditional qualitative literature review. There is a considerable variety of methods and, at the same time, a lack of methodological evaluation (Gmür, 2003, Župič and Čater, 2015).

Citations are used in most review papers as measures of the influence of papers (Župič and Čater, 2015). Authors cite documents they consider to be important for their research. Although a citation analysis provides important information on the influence of papers, such as most cited papers, journals or authors, it cannot provide insight into the network of connections among the publications (Üsdiken and Pasadeos, 1995). Contrarily, a co-citation analysis (McCain, 1990) is based on the premise that the frequency of two items appearing together signifies their content is related. This dynamic measure identifies the connections between "subject-matter experts, who cite the papers they consider valuable and/or interesting" (Župič and Čater, 2015). The results reveal the main schools of thought within a field and help detect paradigm shifts (Pasadeos et al., 1998).

The bibliometric tools can be used in research to identify existing connections between authors as well as different subthemes of a field. They provide objectivity by referring to the combined reasoning of the citing authors (Bayer et al., 1990). Additionally, they yield the most influential papers, identify the 'biggest contributors- as well as offer graphical presentations of the development of a research field, e.g. detecting theory streams (Marinšek, 2015). Accordingly, there have been several published papers with co-citation analyses, some of the most recent for example (Mishra et al., 2017, Kilubi, 2016).

Moreover, the results of such an analysis serve as an orientation of the prime papers to start research in an unfamiliar field. In contrast with more standard literature reviews, such an analysis can reveal interrelations across different schools of thought and offers greater objectivity, since it represents the outcome of a "composite judgment of many citing authors" (Backhaus et al., 2011, White and Griffith, 1981, Bayer et al., 1990). Thus the authors are no longer allocated to research areas based on subjective views of the study authors themselves (Ramos-Rodríguez and Ruíz-Navarro, 2004).

We used the Systematic Literature Network Analysis, a two-part methodology, introduced in (Colicchia and Strozzi, 2012): first, the standard literature review approach (Rousseau et al., 2008) offered the initial selection of the most relative papers that were included in the analysis. Second, the citation network analysis (Hummon and Dereian, 1989) provided the selection of papers, based on the citation count - this offers an overview of the development of themes and knowledge within the field. After the standard citation analysis, we also applied the co-citation analysis that searches for conceptual connection among the cited references of 
the final paper dataset. Thus the co-citation results also include contributions which were not part of the original dataset, yet are strongly connected to the initially selected papers.

To obtain all the relevant documents and exclude the irrelevant ones, a set of criteria should be defined. The following set was used to include/exclude papers from the analysis:

- Include only papers published in peer-reviewed journals indexed in the SCI and SSCI of the Core collection of Web of Science.

- Include only papers in English.

- Include papers containing at least one of the keywords.

- Include papers from all periods (from 1900 onwards).

- All abstracts were read to identify any potentially unrelated papers.

The papers were chosen according to a correspondence of keywords, prepared by the authors and assessed and complemented by a group of three external researchers to provide objectivity and validity. The string of used keywords ("business process*" in combination with the keywords "model*", "management", "redesign", "optimization", "re-engineer*", "improvement", "optimizing", and "paradigm") in the titles provided 522 results. The abstracts of these papers were read to exclude any potentially unrelated papers. Typical examples of excluded papers are (Meško and Meško, 1994, Malik et al., 2012, Chang et al., 2009); the whole list is in an online appendix.

The bibliographic data (including the cited references) of the 433 final papers was exported from the Core Collection Web of Science site. Based on the review of the references and the bibliography of the final papers, additional "milestone" papers were added to improve the degree of the literature review comprehensiveness (Colicchia and Strozzi, 2012). Additionally, we used the same keywords in Scopus, checked the hits with at least 100 citations and added one additional paper to the dataset. This resulted in the end dataset of 446 papers.

The collected data was then imported into the bibliometric analysis software BibExcel (Persson, 2009) that produced a co-citation file to be viewed in the Pajek network software program (Batagelj and Mrvar, 1998). We used the standard Louvain method (Blondel et al., 2008) to identify individual clusters. The method uses the network modularity to measure the meaningfulness of network division into clusters. After testing different parameters (resolution parameter set to 1), a set of 8 clusters was chosen. The modularity of the network, which is the measure of meaningfully connected community structures (Newman, 2006), was 0.4933 , which is considered an appropriate value (Newman and Girvan, 2004). Two clusters contained only one item and were treated as an outlier. The remaining 6 clusters were then examined in-depth to identify the prevailing theme of each cluster, thus producing an analysis and visualization of networks of conceptually-related papers.

\section{The evolution of BPM}

It is difficult to say just when (and how) BPM started, since the definition of BPM is still largely inconsistent (Palmer, 2011). Even the first appearance of the term BPM is under dispute; quoting zur Muehlen "In the pre-1990s there has been a lot of use of 'BPM, not all 
traceable" (found in Byron (2009)). While some believe it dated back to the times of the Scientific Management (Taylor, 1911), others might even quote 18th century sources. Regardless, at its core has always been the question of efficiently managing business processes, which in the times of BPR meant how to scrapping existing business processes and create new ones (Anand et al., 2013).

Figure 1 presents the 36 most influential works from the BPM field as identified based on the primary (citation) and secondary (co-citation) analyses of the paper dataset. By also including the co-citation analysis the search for the most influential works was extended onto the cited references of the papers, resulting in a broader scope of research contributions.

The size of each circle represents the importance of a particular work by number of citations, while the thickness of lines among them is dependent on the number of co-citations. Thus thicker lines represent a stronger connection in terms of content. Additionally, papers are presented in a chronological order from the earliest papers on the top of the figure to the most recent ones at the bottom. Obviously, such an analysis is skewed towards older papers (that had time to accumulate citations).

Figure 1: Historical development of BPM

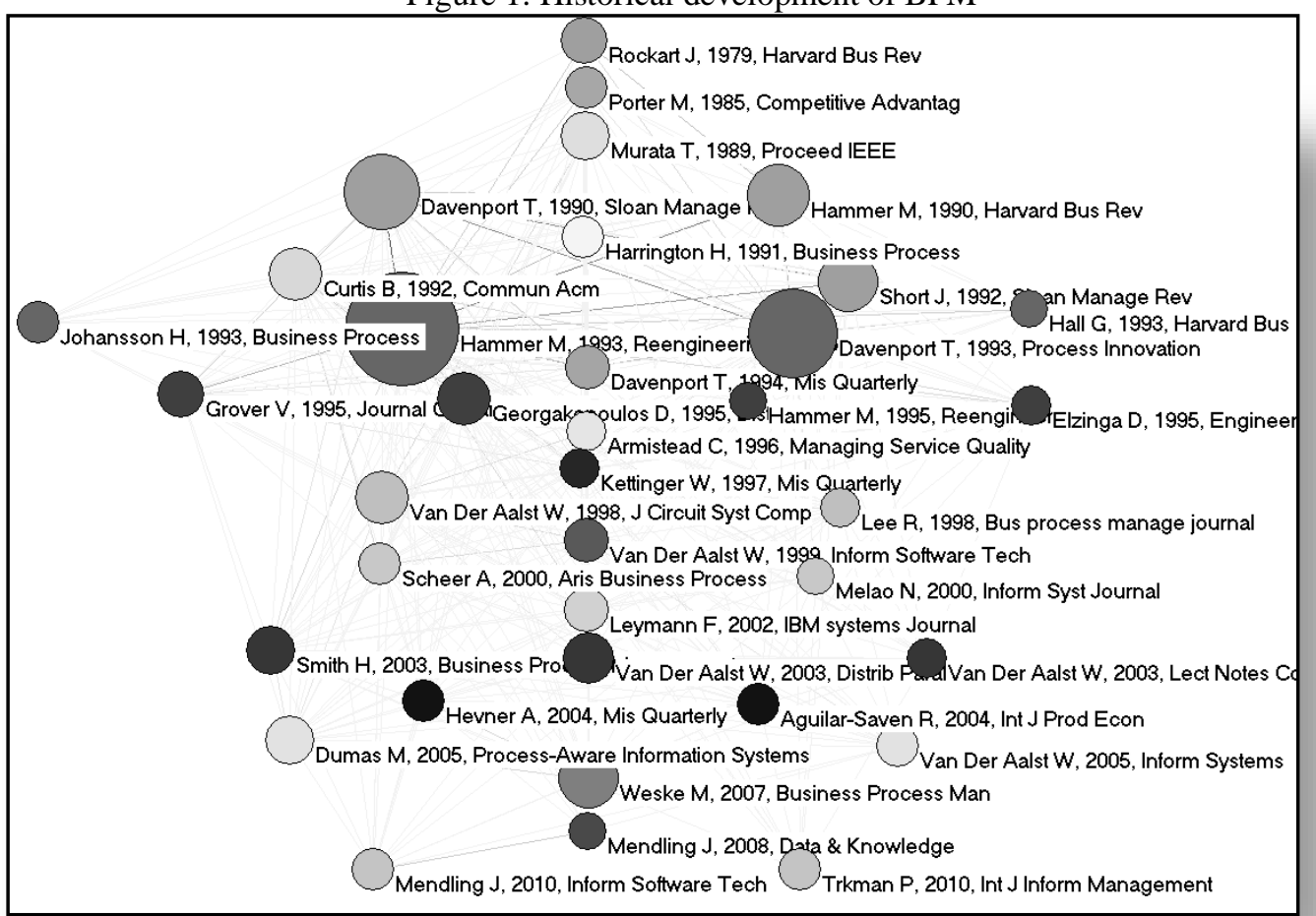


Interestingly the figure begins with two papers; Rockart (1979) and Porter and Millar (1985), not intuitively connected with BPM. However, their focus on various aspects of organizational improvement matched BPM objectives. The first introduced the concept of critical success factors, the later identifies the strategic advantage of information technology in achieving competitive advantage. Though Porter had already been considered a leading business strategy theorist, it was his work on competitive advantage that championed value chains, combined from strategically organized activities, as the basis for competitive advantage of companies (Harmon, 2010).

The paper by Murata (1989) marked the beginning of strongly process oriented works (in our evolutionary tree) with the introduction of Petri nets, a tool for identifying information processing systems that proliferated in the research literature. Part of the reason why Petri nets have been so favored among the workflow technology systems might lie in the fact that Petri nets were already being used to model office procedures in the 1970s. Skip Ellis, Anatol Holt and Michael Zisman already used explicit process models as part of their office in-formation systems (Ellis, 1979; Holt, 1985; Zisman, 1977). Next to the familiarity, ease of use might have been another important argument for the proliferation of Petri net use - as stated by van Hee (2002) - Petri nets enable even non-expert users to easily comprehend definitions and facilitate communication among users and designers.

After being introduced in the 1990s, BPR quickly became popular with companies, rapidly reaching the status of a silver bullet (Melão and Pidd, 2000). The groundbreaking paper by Hammer (1990) introduced the new concept of Business process reengineering (BPR), which advocated radically redesigning processes to achieve considerable improvements in cost, services and quality (Ozcelik, 2010). Hammer's call "Don`t automate, obliterate" best portrayed the practice-oriented start of BPM and its focus on managers. Simultaneously, the paper by Davenport and Stoddard (1994) identified the capabilities of information technology to redesigning business processes.

While BPR was quite the hype, fuelling many company expectations, its read-repeat approach let many unfulfilled. During the BPR 'phase' the first contributions involved success stories of companies (e.g. Ford's accounts payable department, IBM Credit Corporation) employing radical managerial approaches to process improvement, published in managementoriented journals, such as e.g. Harvard business review. Sparking interest in the manager community, BPR soon came under criticism from the research community for inducing more myth than practical methodology (Davenport and Stoddard, 1994).

Melão and Pidd (2000) argued that despite dissipating at the turn of the century, the "reengineering movement" solidified the notion of the process being the core interest of organizational analytics, managerial decisions and performance measures. According to Dumas et al. (2013) BPR eventually faded out due to concept misuse, over-radicalism and unavailable or insufficient tools and technologies.

The next thematic focus of BPM is on our evolutionary path signaled by Curtis et al. (1992). Process modeling has nowadays gained enormous momentum and fostered interest both in the academic community and industry (Mendling, Reijers, \& van der Aalst, 2010) yet researchers at that time still focused heavily on BPR. Johansson (1993) explained the need to 
move beyond approaches like total quality management and continuous improvement to BPR. Similarly Hall et al. (1993) also drew from an array of successful reengineering experiences and identified breadth (defining the redesigned process in terms of cost or customer value broadly) and depth (penetrating various layers, e.g. organizational structure, information technology, skills, etc.) as two critical success factors for reengineering success.

A series of works identified the possibilities that BPM brought; Elzinga et al. (1995) identified BPM as a new possibility to improve company productivity, Armistead (1996) acknowledged the increasing shifts from functionally-based organizations to business process-based and Lee and Dale (1998) provided an overview of the BPM field. The latter researched literature to identify the BPM definitions and critically assessed the application of BPM principles in the organization in comparison with best practice examples found in the literature.

Van der Aalst (1998) applied Petri nets to workflow management and thus provided a new solution for supporting business processes. This novel explicit representation of business process logic enables computerized support. As workflow technology was traditionally used for strongly process-oriented applications high in volume and following similar repeatable processes, the connection to the "early" BPM, which dealt with optimizing manufacturing processes, was very strong (Lin et al., 2002). In the next paper, van der Aalst (1999) addresses the drawback of event-driven processes (EPC), namely their ill-defined semantics in process modeling. He turns to Petri nets and by mapping the EPCs onto them provides formal semantics for EPCs. Scheer and Nüttgens (2000) presented a business process architecture, based on combining both the "content-driven" and "technology-driven" approach leading to a novel process-oriented software concept.

The paper by Leymann et al. (2002) marked the beginning of a transition towards a more holistic perspective of BPM. It addressed the concept of BPM as leverage to transfer the BPR results into production. Hevner et al. (2004) provided a conceptual framework and guidelines for understanding and defining the design-science research within IT. While this paper is not directly related to BPM, it signalizes the importance of creating new and innovative artifacts that bolster the analysis, design, implementation, management, and use of BPM-related solutions. At the same time, Aguilar-Savén (2004) identified a lack of structure and classification of business process models and prepared a review of all currently known business process modeling techniques.

Modeling has always been a core of BPM activities and process models have always been employed for organizational improvement (Adamides \& Karacapilidis, 2006). Originating as early as the early 20th century, Gantt charts and flow charts were some of the earliest business process modeling techniques (Aguilar-Savén, 2004). The term "business process modeling" was coined by S. Williams in 1967 (Williams, 1967), but it was not until the 1990s when modeling became popular. Not surprisingly, the hype around business process modeling was fuelled by enormous practitioner interest (Recker \& Mendling, 2015). Papers such as Mendling et al. (2008) presented insights on model design errors, identifying the correlation between business process model complexity and error probability in event-driven process chains. A few years later, Mendling, Reijers, and van der Aalst (2010) introduced seven principles for business process modeling that translate research finding into practical guidelines for process designers. 
The field of BPM evolved rapidly and in the following years many authors presented the state-of-the-art research on BPM in monographs or referenced works. Two of the most influential are the book, edited by Dumas et al. (2005), which was an overview of the current knowledge on process-aware information systems. It extensively covered the concepts, the techniques, modeling languages as well as the standards and tools of contemporary BPM. Weske (2007) discussed the underlying principles of BPM in his book, introducing the core concepts of BPM before focusing predominantly on process modeling techniques and process enactment platforms. The last contribution is the paper by (Trkman, 2010) which uses a theoretical framework combining dynamic capabilities, task technology fit and contingency theory to derive the critical success factors of BPM.

\section{The fundamental themes of BPM}

The cluster analysis of the 150 most cited contributions, according to the co-citation results, provided 6 clusters that we thematically analyzed and presented the core contributions of each cluster. In order to contribute to an even more comprehensive field overview, another qualitative selection of papers was performed. While the co-citation analysis contributed to the field exploration by analyzing the original dataset references to produce an augment dataset of the most highly cited contributions, it is understandable that it cannot feature all relevant contributions. Assessing that some pertinent content-related papers were omitted and therefore also not featured in the clusters, we researched and included additional papers on connecting or similar content but from various disciplines. While the concepts are similar, the terminology is sufficiently different that the papers were not included in the co-citation analysis.

\subsection{Cluster 1:Practice-oriented BPR}

The intellectual structures of both clusters 1 and 2 concern the early wave of managing business processes, featuring the more radical approach to business process optimization business process reengineering (BPR). Since BPR was first of interest to the industry, the first papers in Cluster 1 (shown in Figure 2) were based on case studies and thus published in more practice-oriented journals, such as Harvard Business Review and California Management Review.

The distribution of the nodes thus implies that it was BPR that shaped the following generations of academic and industry research into today`s field of BPM. Found in the core, Hammer and Champy (1993) acts as a basis for much of the following work on BPR. The proponents of BPR argued for a complete restructuring of organizations, following the "allor-nothing" doctrine of Hammer. Afterwards, IT-enabled BPR (signaling IT automation of business processes) papers start appearing, signaling the change from 'simple' process reconfiguration of early BPR to more elaborate and comprehensive organizational change (Teng, 1996). 
Figure 2: Cluster 1: Practice-oriented BPR

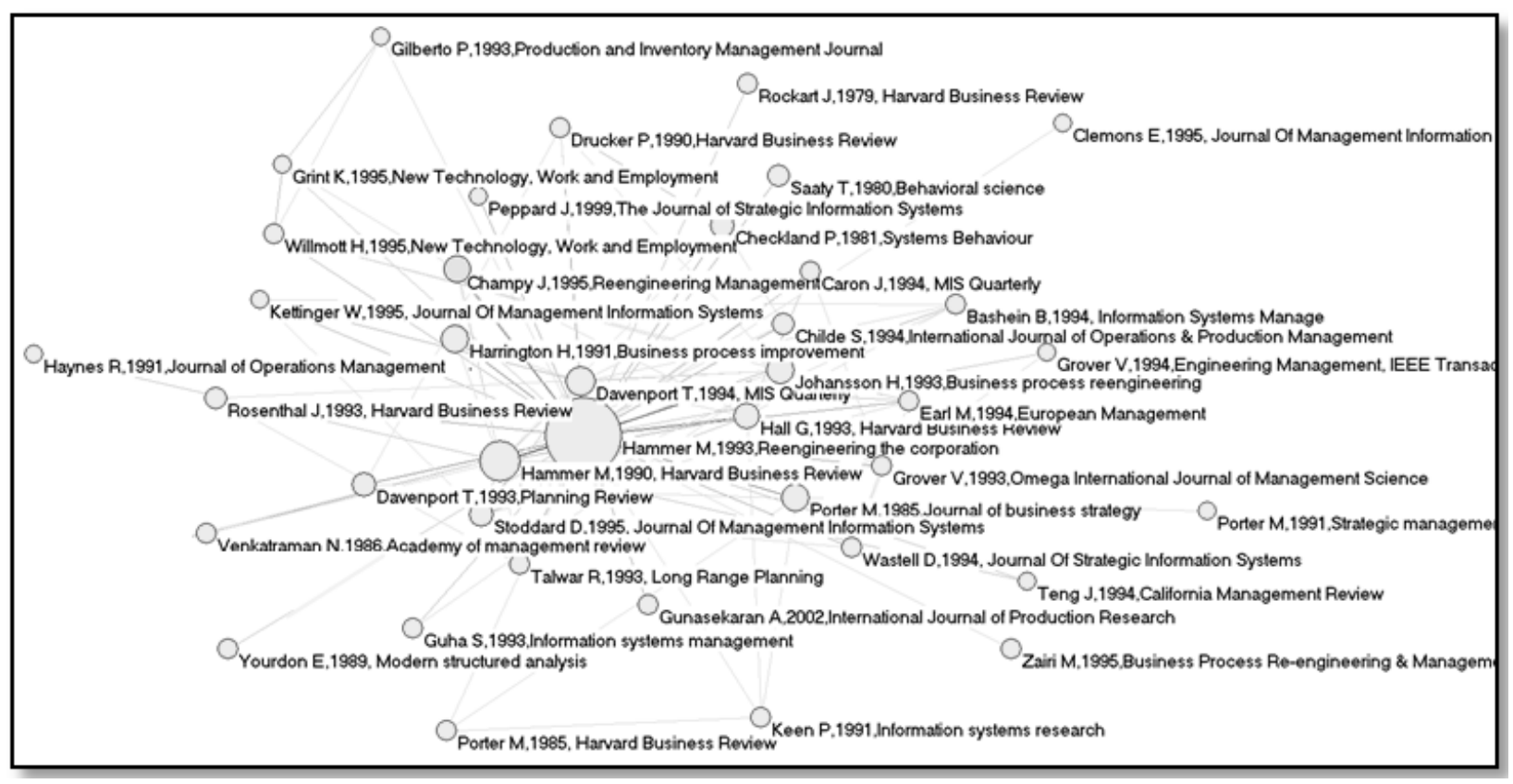

Later contributions focused more on BPR from a theoretical rather than a practical perspective. Childe et al. (1994) took on the theory-based approach to BPR by identifying the stateof-the-art body of knowledge and the lack of agreement over the meaning of the term "process". Davenport and Stoddard (1994) stressed the need for demythologizing BPR and some of its key aspects to familiarize the practical methodology regarding reengineering. Clemons et al. (1995) identified functionality risk and political risk as two of the main reasons for BPR initiative failure.

Although dealing with the same objective as BPR, i.e. the increase of organizational effectiveness and performance Porter (1979), Venkatraman and Ramanujam (1986) and Rockart (1979) represent the rim of the cluster, since their focuses are not business processes. The predominant focus of this cluster is on business processes and improving them to increase business performance. Thus redesigning or even obliterating business processes is only one of a series of possible approaches that companies adopted during the early 1990s to improve their company performance. Among other possibilities were Total Quality Management (TQM), embracing the strict principles and techniques of continuous improvement and for quality control, Lean, focusing strongly on eliminating non-value adding activities, or Six Sigma that aimed primarily at minimizing errors (Dumas et al., 2013).

Connecting to the wider literature, BPR can be considered to fall under the umbrella category of organizational change management, along with other strands of work, such as the theoretical concept of organizational routines or resistance to change. Intrinsically, these contain a special element of flexibility or context-awareness, that still seems to be missing from BPM (vom Brocke et al., 2015). While the importance of flexibility and agile processes were by no means a novelty for the BPM community (see e.g. (Pesic and van der Aalst, 2006, Sadiq et al., 2005, Burmeister et al., 2006, Bruno et al., 2011). BPM still seemed to be struggling with 
the "art or science" predicament (Hall and Johnson, 2009) of wanting to structure and organizes processes that are inherently 'messy', because they are influenced by the social systems that the process is embedded in (Beverungen, 2014).

In Pentland and Rueter (1994) the authors focused on exactly those kind of work processes in a task unit, where the work involves high numbers of exceptions, frequent interruptions, low analyzibility of search. Despite the fact that no traditional definition would characterize such a process as routine, it produced a repetative, functionally similar pattern of action (Pentland et al., 2010). Consequently organizational routines were defined by Pentland and Feldman (2008) as "generative systems, producing repetitive patterns of interdependent actions, carried out by multiple actors". Beverungen (2014) for example provided the theoretical contribution that business processes should be understood as particular organizational routines.

\subsection{Cluster 2:Workflow Management}

The second cluster (Figure 3) is strongly influenced by the contributions of van der Aalst and co-authors and organized around the subtheme of orchestrated and repeatable business process patterns - workflows. Centrally we find (van der Aalst, 1998) which introduced the concept of designing processes with Petri nets to create cross-department sequences.

Figure 3: Cluster 2: Workflow Management

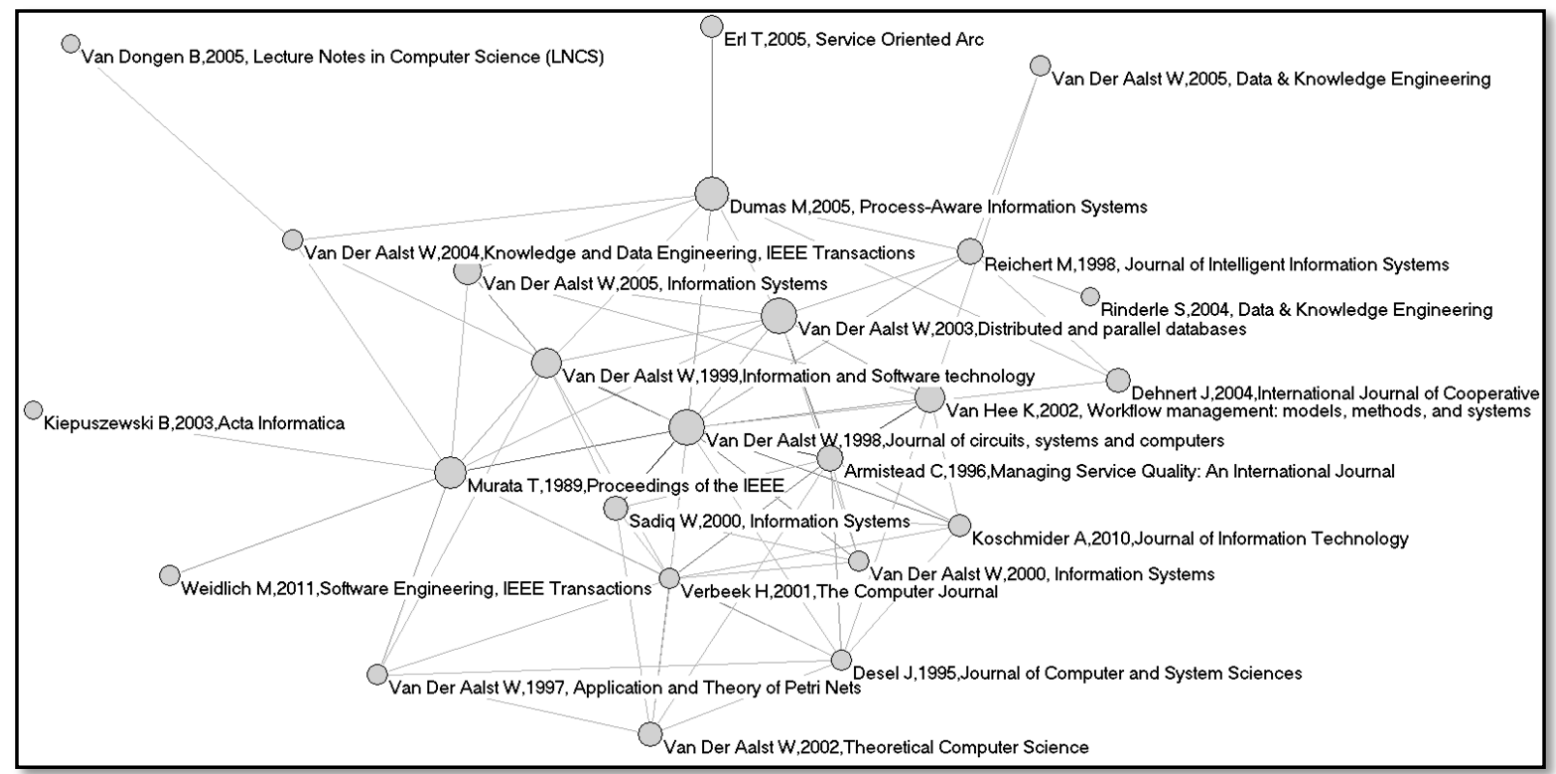

In the next years other contributions expanded the knowledge on workflow management in 3 areas:

1) Several papers explored the tools of workflow management, mainly focusing on Petri nets. Van der Aalst (1999) mapped event-driven process chains to Petri nets. The paper by Murata (1989) preceded the core paper in introducing the properties of Petri nets, as well as the procedures of analysis and application. For example, Dongen et al. (2005) presented a 
framework for one-size-fits-all mining infrastructure. Despite not being featured in this cluster, there are also other, alternative methods and tools, such as design structure matrix (DSM), Critical path method (CPM), Programme Evaluation Review Technique (PERT), textual narrative, Gantt chart to name only a few. These represent some of the many possibilities of process model views, each yielding a different model with a different intent or focus (Browning, 2009).

2) The cluster also contains several papers on techniques, e.g. by Weidlich et al. (2011) on enabling consistency evaluation based on model behavioral constraints or Sadiq and Orlowska (2000) on the benefits of model analysis through graph reduction techniques. Van der Aalst and Song (2004) developed a mining algorithm for addressing the workflow rediscovery issue.

3) The final area of the workflow cluster features conceptual contributions - as an academic response to the findings of consulting companies van der Aalst et al. (2000) introduced a comparison of 12 workflow management systems. The book by van Hee and van der Aalst (2002) presented an overview of workflow terminology and organization, as well as workflow modeling with Petri nets.

Connecting to the wider literature, the current, fairly narrow focus on workflow management in this cluster could be expanded by exploring the many contributions discussing both BPM and neighboring fields such as (software) project management or software development. Project management is often identified as a critical success factor (CSF) of BPM (Trkman, 2010), accordingly specific approaches such as project scheduling are of obvious practical importance. The paper by Herroelen (2005) on the use of process models for project scheduling is thus an appropriate example of the connection of the two management fields. BPM researchers have also explored model-driven approaches to software development (Bettin, 2004, Vidales et al., 2008). Software-oriented journals, e.g. Journal of Software Maintenance and Evolution featured papers exploring the possibilities of coupling BPM with social software such as Erol et al. (2010) or Bruno et al. (2011). Taking on adapting workflows to the modern demands, papers such as Sadiq et al. (2005) have expanded the range of workflow usefulness and ability.

BPM research has also delved more deeply into adaptation and quick response with contributions such as Burmeister et al. (2006), Lin et al. (2002), Silva et al. (2010), Pesic and van der Aalst (2006). Fowler (2001) found that while engineering methods favor planning out in great details as definite as possible, agile methods are adaptive instead of predictive.

\subsection{Cluster 3: BPM concepts}

Cluster 3 (shown in Figure 4) features diverse contributions that introduce and explore different BPM concepts such as business process modeling, and business process change. The cluster network features several authors dealing with modeling, modeling techniques and methodologies as fundamental aspects of BPM (Aguilar-Savén, 2004, Curtis et al., 1992, Leymann and Altenhuber, 1994). Another set of publications researched the theoretical and methodological fundamentals of concepts like business process change, i.e. Kettinger et al. (1997) 


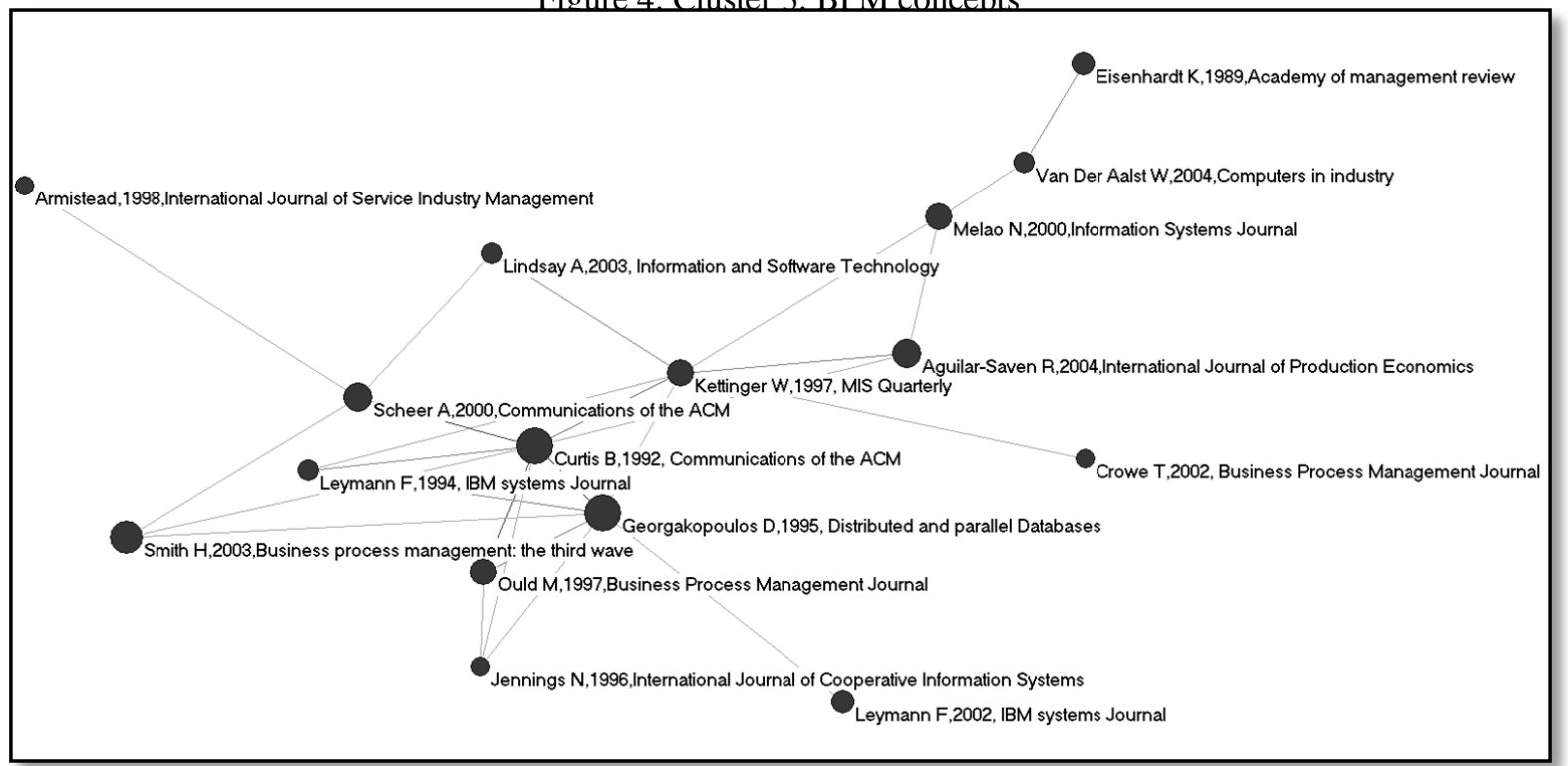

Similarly Melão and Pidd (2000) prepared a conceptual framework aimed at organizing the different views of the nature of business processes. Focusing on determining the process architecture, Ould (1997) introduced a method to aid process identification, definition and modeling. Considering the three main thematic focuses of the cluster (processes, business process modeling and business process change) we term the cluster BPM concepts for its focus on introducing and identifying the various concepts.

Connecting to the wider literature, this cluster could reach out to other management fields, most notably on a specialized environment of modeling, namely modeling processes intended for product development. The process in this context is understood as a kind of system that can be engineered (Browning et al., 2006). Accordingly, research focused on process modeling frameworks, exploring how to increase applicability, maintainability and reusability of process models for product development, and also for knowledge management and software development (Casati and Discenza, 2001, Browning and Ramasesh, 2007, Ballou et al., 1998).

\subsection{Clusters 4\&5: Business process modeling - Methods \& Information Technology}

The subtheme of business process modeling then underwent proliferation phase, represented by two following clusters, clusters 4 and 5 . Both clusters deal with business process modeling, yet they differ in their approach to and understanding of modeling. To convey the difference we use the Rosemann and vom Brocke (2015) well-defined factors that together constitute a holistic understanding of BPM (De Bruin, 2009). Cluster 4 studies a set of tools and techniques supporting activities from the process life-cycle (Rosemann and vom Brocke, 2015), cluster 5 explores modeling as an IT-based solution for increasing process awareness, usually manifested as a process-aware information system (Dumas et al., 2005). 
Both clusters 4 (in Figure 5) and 5 (in Figure 6) deal with business process modeling performance. Cluster 4 (Business process modeling - Methods) is the second largest in size, thus signifying the resonance of the theme within the BPM field, and together with cluster 5 (Business process modeling - Information technology) represent business process modeling as the most researched of the found BPM subthemes.

Figure 5: Cluster 4: Business process modeling - Methods

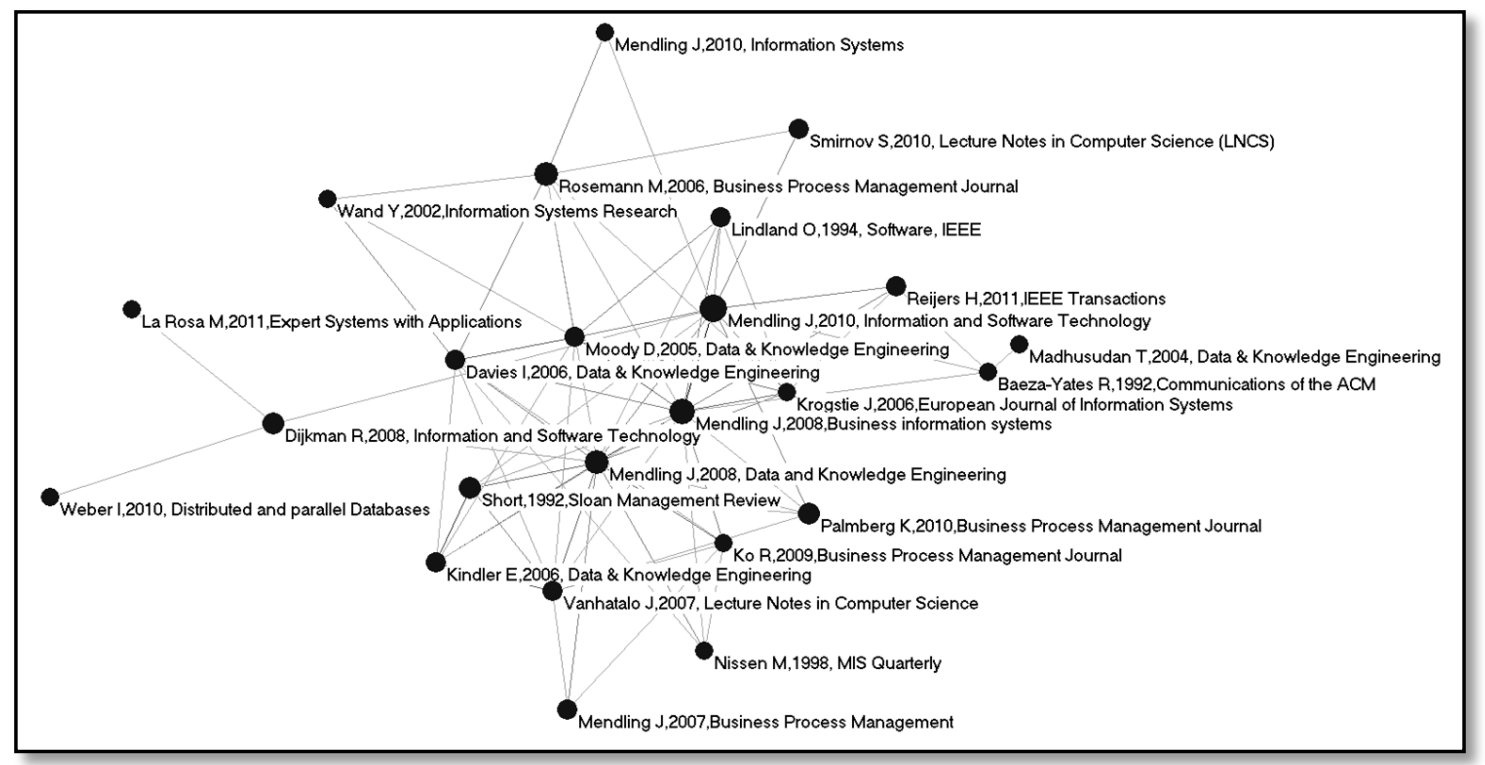

Cluster 4 has an abundance of papers by a younger generation of researchers, strongly marked by contributions from Mendling. The spotlight had shifted towards establishing guidelines for successful business process modeling - the majority of works within the cluster feature issues with quality measures. Accordingly, Mendling and Strembeck (2008) explored a particular quality aspect of business process models - understandability. Similarly, Mendling et al. (2010b) addressed the low level of modeling competence by introducing seven process modeling guidelines, while Mendling et al. (2010a) examined activity labeling practices in process modeling. Identifying the lack of data on errors in process model collections, Mendling et al. (2008) analyzed a set of models to explore model error occurrence.

Some works addressed issues with business process modeling notation; e.g. Dijkman et al. (2008) proposed a mapping from BPMN to Petri nets, due to their more efficient analysis techniques. Krogstie et al. (2006) revised quality framework, as an answer to the identified "need for a more dynamic view in the semiotic quality framework". This cluster also includes some non-process-modeling works, such as Short and Venkatraman (1992), stating the need to shift from business process redesign of internal operations to reconceptualizing the company role within a larger business network. 
Figure 6: Cluster 5: Business process modeling - Information technology

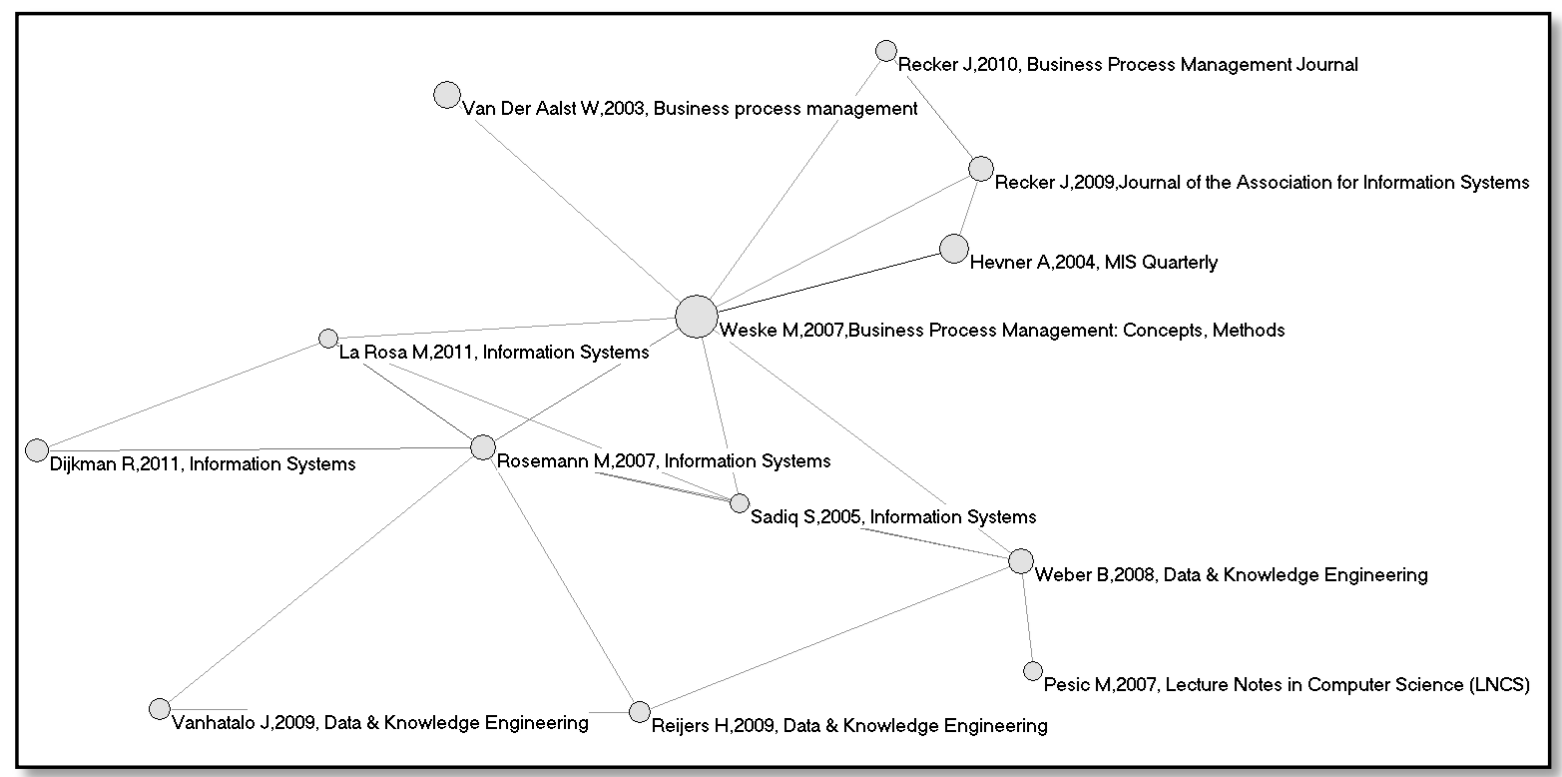

Cluster 5 seems a very technology-oriented cluster, focusing on improving business process modeling for industry. With processes steadily becoming more knowledge-intensive and thus unpredictable and prone to change, the standard process management techniques, intended for predictable processes, seem more and more obsolete (Di Ciccio et al., 2015).

A subgroup of papers within this cluster thus answer the calls for greater model adaptation to the "presence of change" in business processes (Sadiq et al., 2001). Reijers et al. (2009) focused on similarly executed processes within one single model and provided an aggregated model that can represent them. Similarly, Dijkman et al. (2011) proposed three similarity metrics to ease identifying similar business models from model repositories. By proposing a new workflow language, Pesic et al. (2007) offered more flexibility in the standard model management approach. Weber et al. (2008) also advocated flexibility in process-aware information systems by proposing model patterns and change support features that better answer to the changes in processes. Sadiq et al. (2005) provided process constraints that counteract flexibility aims to enable an appropriate balance of modeling business processes. Another subgroup of this dichotomous cluster featured a set of viewpoint contributions, dealing with model notation problems Recker (2010) and enterprise modeling guidelines (Weske, 2007). Answering the existing research gap, La Rosa et al. (2011) introduced a configurable process modeling notation for capturing resources, data and physical objects involved in the performance of tasks.

Connecting to the wider literature, we explored some additional papers on process modeling. Models in their essence are intended to convey necessary information about the process, yet conveying too much can render them cumbersome and difficult to use or understand. Already very early on, research showed that despite being less informative, managers prefer simple models (easier to understand and control), to more realistic ones (Little, 1970). Thus in order to contribute to the understandability of models several researchers focused on developing 
guidelines on (successfully) modeling processes. Interestingly, while some papers on guidelines, such as the 7 modeling guidelines of Mendling et al. (2010b) were featured in cluster 4, others such as Becker et al. (2000) were not. Various frameworks for understanding quality of process modeling techniques quality were also developed, like the Quality based modeling evaluation framework by Hommes and Van Reijswoud (2000), aimed at assessing both the product quality and process quality of modeling techniques, using a specific set of predefined properties. Another systematic approach for measuring the qualities of modeling techniques are complexity metrics (Rossi and Brinkkemper, 1996).

Apart from evaluating the techniques and methods, research also focused on the quality of process models themselves. While the quality issues cannot be exhaustively evaluated, there are four main guidelines and framework dedicated to assessing process model quality, namely top-down quality frameworks, empirical surveys related to modeling techniques, bottomup metrics related to quality aspects, and pragmatic guidelines (Mendling et al., 2010b). The semiotics-based SEQUEL (Lindland et al., 1994, Krogstie et al., 2006) was a top-down quality framework that encompassed multiple quality aspects (van der Linden and Hadar, 2016). There were also several works on bottom-up metrics, related to the quality aspects of process models (Mendling, 2007), such as Canfora et al. (2005) on the connection between count metrics and maintainability of software process models, or Cardoso (2006) on the correlation between control flow complexity and perceived complexity.

Also congruent to process modeling are software process modeling contributions, such as e.g. (Finkelstein et al., 1994), which presented an overview of the software processing field and identifying key research problems. Another highly cited paper, Yu and Mylopoulos (1994), presented a model of the intentional structure of a software process and embedding organization. By addressing not only the 'whats' of software process models but also the motivations and rationales behind the activities ('whys'), the authors contributed to the understanding of software process complexity.

\subsection{Cluster 6: BPM success factors}

In the final cluster, cluster 6 (in Figure 7), the focus is on the search for a more successful BPM by enabling a clearer understanding of the concept and its components. Trkman (2010) applied a combination of three theories for theoretically grounding the BPM concept, identifying 12 critical success factors as "a basis for the explanation of (un)successfulness of BPM efforts". Earlier, Ariyachandra and Frolick (2008) proposed a set of critical success factors, yet without a theoretical framework. Zairi (1997) focused on the process, proposing guidelines for sustaining BPM as well as establishing a "culture based on BPM". Similarly, Hung (2006) in his review of BPM as a competitive advantage, assessed the effects of two key concepts in BPM implementation. The groundwork for this though seemed to be the paper by Hammer (2007) found on the outer rim of the cluster. He focused on the methodology of doing BPM 'better' and attempting to understand what BPM actually is. 
Figure 7: Cluster 6: BPM success factors

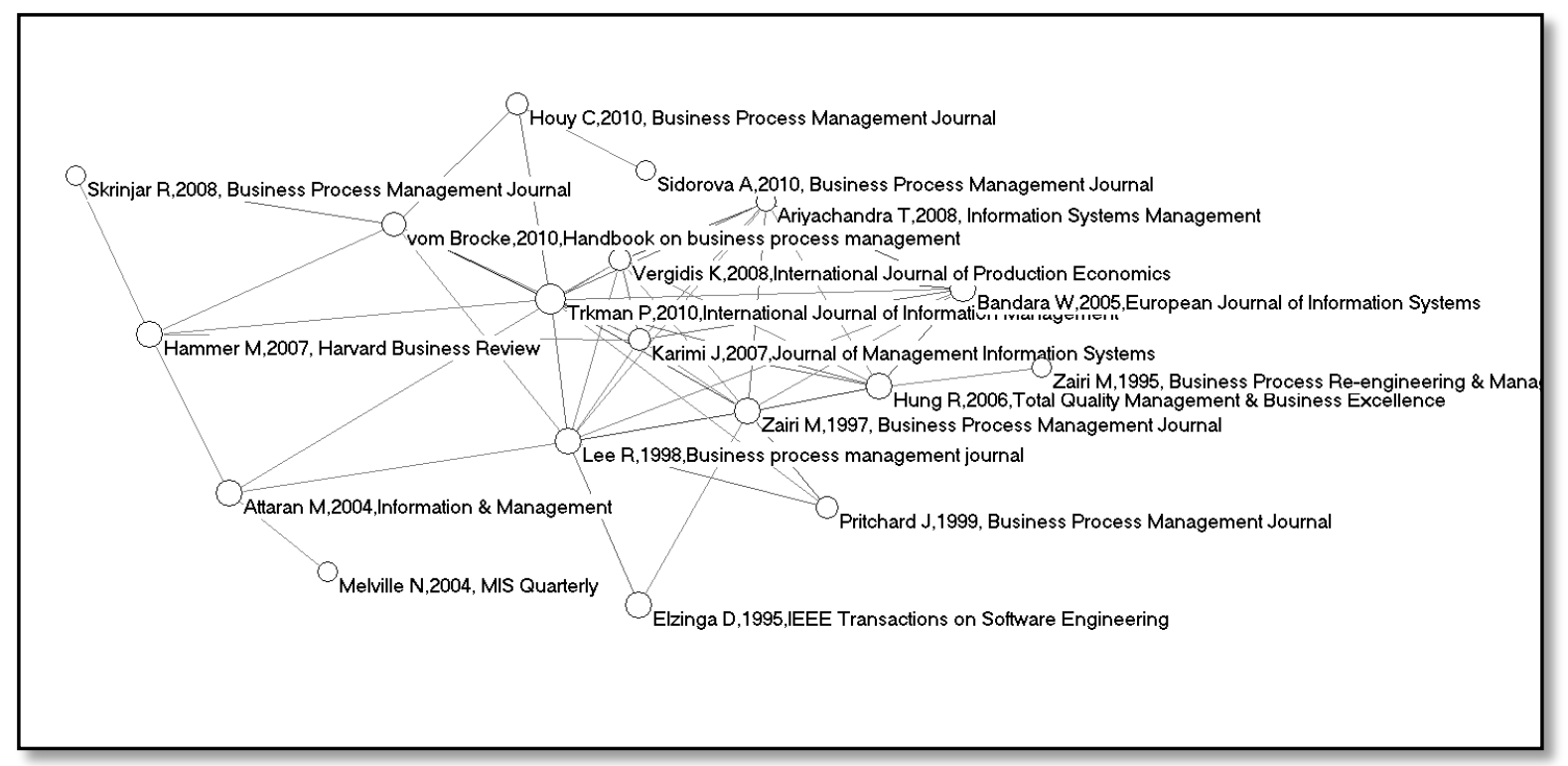

Sidorova and Isik (2010) focused on identifying the core of business processes. The resulting center was composed of process design, technologies, implementation, and management. Similarly, Vergidis et al. (2008) provided an overview of business process perspective and investigated the state-of-the-art in research and practice. Karim et al. (2007) proposed enterprise resource planning systems as a key determinant for optimizing business process outcomes.

Connecting to the wider literature, the contributions on organizational processes, especially the research literature on organizational routines, was definitely under-used by the papers in this cluster. In their desire for better structure and understanding of processes, many researchers focused on analyses of organizational processes. Malone et al. (1999) developed a new approach to analyzing processes - at various levels of abstraction. They tackled the challenge of representing organizational processes by organizing similar processes of different organizations into a process 'handbook'.

Organizational routines focus on patterns of action as their main unit of analysis (Pentland and Feldman, 2005). Exploring beyond the surface-level data, Pentland (1999) focused on narrative for analyzing organizational processes as a means to enrich process theory. Similarly, exploring the effect of micro-level actions in routines on macro-level phenomena such as dynamic capabilities, Pentland et al. (2012) prepared a generative model of organizational routines and their change over time. 


\section{The future of BPM}

In the past few decades, BPM has often been labeled as hype-driven (McCoy, 2010, Dadam, 2008, Jeston and Nelis, 2008). This can also be deduced from the apparent fragmentation of the BPM field as per the cluster analysis and the derived different subthemes. Recently there has been a rise of new concepts such as digital transformation, business innovation (vom Brocke, 2016), stirring new hypes in the management community. Adopting the perception of Pascale (1990) that all popular management notions have a life cycle, could these new concepts denote the possibility of BPM beginning its slope into demise?

Years ago, the field had undergone a conceptual transition - namely it changed focus from the more radical BPR that relied on its success stories to workflow management. Taking a look at the current state of BPM, it becomes apparent that this concept misuse and lack of consensus seems to be a recurrent theme in the BPM history and possibly one of the reasons for its periodic "reinventions". Faced with the appearance of new management hypes BPM now seems on the brink of yet another revamping.

In line with this it seems that the BPM field has reached a certain standstill, where it appears to have restricted itself increasingly to "identification, modeling/representation and mining of processes". BPM is at an important crossroad: with all the hype about digital transformation/ internet of things (IoT)/ social networks and related concepts, the question is whether the field will be able to re-invent itself to be a cornerstone of the research of the processes in these areas. Will BPM be able to offer theoretical insights, new artefacts and tools for mobile processes execution? Will it enable the leveraging of social media for process innovation (see Trkman and Klun (2015)) or to enable new or improving existing business processes or capabilities (Melville et al., 2004, Trainor et al., 2014) of companies to better use social media in general? Will theory development on 'digital transformation' (see e. g. Majchrzak et al. (2016)) draw from the BPM body of knowledge? Such research should be appealing both to the most prestigious journals in management and IS and to C-level executives.

However, as indicated by our co-citation analysis, it has not (yet) occured. Further, none of the 300 most cited papers with the term "social media" in the abstract, title or keywords uses the term "business process" anywhere in the abstract or keywords (search in Scopus on May, 10 2017). On the other hand, a recent special issue on IoT in the Business process management journal is an important step in the right direction. It investigated both the impact and the role of IoT on BPM in terms of promotion of knowledge flow, innovation and competitiveness (Del Giudice, 2016).

We argue that BPM and its contributions are simply "too big to fail". Considering the several decades of research and practice that have been invested in the BPM field and generated an extensive body of knowledge, it would be a disaster to let BPM become replaced by trendier concepts (vom Brocke, 2016). In 2010 Harmon discussed the future of BPM as being certain in the sense that companies will continue to focus intently on improving the way they manage the business, regardless of the denomination (Harmon, 2010). Accordingly, the only alternative left for BPM is indeed to transform itself. 
The analysis of the identified six clusters along with the co-citation analysis have demonstrated that BPM is far more fragmented and niche-oriented than its definitions describe. Our results have suggested that BPM is, in fact, neither truly holistic nor managerial (anymore). Despite starting out as strongly management-focused, BPM has drifted into the domain of scope-bounded journals (e.g. Information and Soft-ware Technology) in academia and IT departments in companies. While as a field, BPM seems very fragmented, there are calls and attempts of focusing on BPM as a whole - denoted by the contributions in the final cluster that is devoted to finding possibilities for improving BPM. One such possibility for improving BPM is expanding it to involve not only an organizations` customers but also their processes. As stated by Trkman et al. (2015) gaining more information about the customer processes means the company can gain a deeper understanding of their customers and their behavior, and where needed adjust all necessary processes to it. The role of BPM in the digital world has already received much attention (Loos et al., 2015; Meyer et al., 2013; Recker, 2015; Schmiedel \& vom Brocke, 2015) and with so many data available online, taking advantage of the 'digital wave' might prove the next best step for BPM. Giving BPM a more uniform, 'digitally-inspired' re-packaging might also make it more appealing to managers and management journals.

Currently, BPM can be said to still embody some of the concepts according to Davenport and Stoddard (1994), having in the past discarded the concepts pertaining specifically to BPR, such as promoting a "clean-slate" approach to process design and radical change of process performance. We propose to update their concepts in order to better embody BPM in its current and desired future state:

1. Business processes are the fundamental unit of analysis of organizational design and change.

2. Organizational procedures are identified and visualized as business process models.

3. Business process changes are felt on all organizational levels thus they must be reflected in human arrangements that accompany change.

4. Business process management is able to help in implementation of any kind of organizational changes when needed.

5. Business process experts should clearly identify the contribution of a certain BPM technique and position it in relation with other fields.

BPM should thus avoid the tendency to define itself as an all-encompassing field and hiding behind generic terms such as 'holistic approach' and 'process orientation'. On the contrary, BPM should strive to provide in-depth, hands-on theoretical knowledge and practical tools. BPM needs to escape the entrenchment of fragmentation and indistinct-ness as a field, and one possibility is to focus more on the company needs of developing in-house expertise to quickly respond to business changes. BPM researchers need to develop more in-depth theories, which will help to change the perceptions of business processes - understanding them more as organizational routines, i.e. generative systems producing patterns, made up of interdependent actions among multiple actors (Pentland \& Feld-man, 2008).

While we believe that such a path is possible, BPM can alternatively deliberately limit itself to the currently largest subtheme of business process modeling, namely by investigating how to model the processes more comprehensively and use the process models for improving the understandability of the processes and the support of workflows with IT. 
In any case, the afore mentioned definition of BPM as "holistic management approach that focuses on aligning all aspects of an organization with the requirements of their customers" (vom Brocke and Rosemann, 2010) should be changed accordingly to reflect what BPM wants to be.

\section{Conclusion}

This paper contributes to the current knowledge on BPM in the following stages: first, by applying the novel research approach of a combined literature review, introducing a dynamic representation of the field development and main thematic components. Second, exploring and delineating the BPM field with the cluster analysis offered a comprehensive overview.

The combination of the co-citation and cluster analyses offers joint perspectives on the most influential works and most prolific themes within BPM. Third, in agreement with Lyytinen and King (2004), we acknowledge that also in the field of BPM the researchers should be akin to "falcons in the ever growing gyre of the IT revolution". The definition of the BPM field should thus be more descriptive and not prescriptive and should focus more on "the vast market of ideas" as suggested by Lyytinen and King (2004), rather than on searching for a fixed core theory.

In an answer to calls that BPM is not engaged at all in the wider literature on organizational change and therefore the current research is hard to place within a clear, identifiable theoretical approach, the paper argues that rather than directly defining the limitations and boundaries of the BPM field, it is better to let the field define itself. This paper contributes to the identification of the BPM field by providing an array of BPM-grounding papers that shape and drive the field, thus constituting a "polycentric core", similar to Taylor et al. (2010)'s description of the IS discipline. Further, we try to position each cluster within the wider literature by also subjectively reflecting on related fields to each cluster.

This paper represents an overview of the BPM field by combining two important perspectives - an evolutionary and a point-in-time observation of BPM and its most pronounced themes. Although intrinsically defining itself as a management field, and thus per se close to operations management or strategic management (see e.g. Elzinga et al. (1995), Dumas et al. (2013)), BPM nowadays seems more at home as an important sub-domain of the IS discipline (Sidorova et al., 2008). This notion of BPM connecting more strongly to IS is also supported by our co-citation analysis. One can infer a shift in the journal outlets based on the central papers of each cluster, where the earlier papers were predominantly published in management-oriented journals, such as Harvard Business Review or Academy of Management Review, the latter in scope-bounded journals such as Information and Software Technology, Data \& Knowledge Engineering or International Journal of Production Research. However, this connection to information systems brings with it both advantages and disadvantages, as mentioned by (McAfee \& Brynjolfsson, 2007), since information systems can offer new possibilities for process improvement, but also limit their improvement.

The paper has several limitations: the scope and combination of the keywords meant that some influential papers stemming from this field potentially became excluded from the com- 
piled list. Also by using the SCI/SSCI, papers published in journals that are not featured there (e.g. Business Process Management Journal) were omitted from the initial selection. However, this was adjusted for by using the co-citation analysis since the resulting collection of works was enhanced with new works that had the strongest connections among the cited references. Also, the chosen dataset represents an excerpt from time and future datasets, including a shorter time frame, could produce different results. Such bibliometric indicators are based on bibliographic databases that are primarily intended for providing information about papers, rather than for informetric studies (Hood and Wilson, 2003).

As for future research, the results obtained from the analysis provide the state of the field at a certain point in time, i.e. up to the time of data collection. The time frame dependency of this studied dataset allows for future replications of the analyses to compare the field development at a later stage or at arbitrary time periods in between. Thus subsequent analyses would produce a different outline of the field.

Accordingly, this paper provides a great starting point for multiple detailed explorations of BPM subthemes as well a similar dynamic literature reviews for other fields or for subthemes within BPM. As such it offers suitable milestone in an analysis of which of the two paths BPM will take at its current crossroads.

\section{Acknowledgements}

The authors thank the Slovenia Research Agency (ARRS) for the funding enabling this research. The authors acknowledge the project (J5-6816 Business transformation - from business models to innovative processes) which was financially supported by the Slovenian Research Agency. Additional information and data are available from the authors upon request.

\section{References}

AGUILAR-SAVÉN, R. S. 2004. Business process modelling: Review and framework. International Journal of Production Economics, 90(2), 129-149.

AL-MASHARI, M. 2002. Business process management-a mandatory approach. Business Process Management Journal, 8(1), 1-2.

ALDIN, L. \& DE CESARE, S. 2011. A literature review on business process modelling: new frontiers of reusability. Enterprise Information Systems, 5(3), 359-383.

ANAND, A., WAMBA, S. F. \& GNANZOU, D. A literature review on business process management, business process reengineering, and business process innovation. Workshop on Enterprise and Organizational Modeling and Simulation, 2013. Springer, 1-23.

ARIYACHANDRA, T. R. \& FROLICK, M. N. 2008. Critical success factors in business performance management-Striving for success. Information systems management, 25(2), 113-120.

ARMISTEAD, C. G. 1996. Principles of business process management. Managing Service Quality: An International Journal, 6(6), 48-52.

BACKHAUS, K., LÜGGER, K. \& KOCH, M. 2011. The structure and evolution of business-to-business marketing: a citation and co-citation analysis. Industrial Marketing Management, 40(6), 940951. 
BALLOU, D., WANG, R., PAZER, H. \& TAYI, G. K. 1998. Modeling information manufacturing systems to determine information product quality. Management Science, 44(4), 462-484.

BATAGEU, V. \& MRVAR, A. 1998. Pajek-program for large network analysis. Connections, 21(2), 4757.

BAUMANN, F., EL HUSSEIN, R. \& ROLLER, D. 2015. State of the Art of BPM-Approach to Business Process Models and its Perspective. International Journal of Electronics Communication and Computer Engineering, 6(6), 649-657.

BAYER, A. E., SMART, J. C. \& MCLAUGHLIN, G. W. 1990. Mapping Intellectual Structure of a Scientific Subfield through Author Cocitations. Journal of the American Society for Information Science, 41(6), 444-452.

BECKER, J., ROSEMANN, M. \& VON UTHMANN, C. 2000. Guidelines of business process modeling. Business Process Management. Berlin Heidelberg: Springer.

BENBASAT, I. \& WEBER, R. 1996. Research commentary: Rethinking "diversity" in information systems research. Information systems research, 7(4), 389-399.

BETTIN, J. 2004. Model-driven software development. MDA Journal, 1(April 2004).

BEVERUNGEN, D. 2014. Exploring the interplay of the design and emergence of business processes as organizational routines. Business \& Information Systems Engineering, 6(4), 191-202.

BLONDEL, V. D., GUILLAUME, J.-L., LAMBIOTTE, R. \& LEFEBVRE, E. 2008. Fast unfolding of communities in large networks. Journal of Statistical Mechanics: Theory and Experiment, 2008(10), 1- 12.

BROWNING, T. R. 2009. The many views of a process: Toward a process architecture framework for product development processes. Systems Engineering, 12(1), 69-90.

BROWNING, T. R., FRICKE, E. \& NEGELE, H. 2006. Key concepts in modeling product development processes. Systems Engineering, 9(2), 104-128.

BROWNING, T. R. \& RAMASESH, R. V. 2007. A Survey of Activity Network-Based Process Models for Managing Product Development Projects. Production and operations management, 16(2), 217-240.

BRUNO, G., DENGLER, F., JENNINGS, B., KHALAF, R., NURCAN, S., PRILLA, M., SARINI, M., SCHMIDT, R. \& SILVA, R. 2011. Key challenges for enabling agile BPM with social software. Journal of Software Maintenance and Evolution: Research and Practice, 23(4), 297-326.

BURMEISTER, B., STEIERT, H. P., BAUER, T. \& BAUMGARTEL, H. 2006. Agile processes through goaland context-oriented business process modeling. In: EDER, J. \& DUSTDAR, S. (eds.) Business Process Management Workshops. Berlin: Springer-Verlag Berlin.

BYRON, D. 2009. BPM VIEWPOINT: So Where Does the Term 'Business Process Management' Come From?

Available: http://www.ebizq.net/blogs/bpminaction/2009/01/bpm_viewpoint_so_where_does_th.php [Accessed March 2017].

CANFORA, G., GARCÍA, F., PIATTINI, M., RUIZ, F. \& VISAGGIO, C. A. 2005. A family of experiments to validate metrics for software process models. Journal of Systems and Software, 77(2), 113129.

CARDOSO, J. Process control-flow complexity metric: An empirical validation. Services Computing, 2006. SCC'06. IEEE International Conference on, 2006. IEEE, 167-173.

CASATI, F. \& DISCENZA, A. 2001. Modeling and managing interactions among business processes. Journal of systems integration, 10(2), 145-168.

CHANG, S., NEWELL, J. \& SALMON, C. T. 2009. Product placement in entertainment media: Proposing business process models. International Journal of Advertising, 28(5), 783-806. 
CHILDE, S., MAULL, R. \& BENNETT, J. 1994. Frameworks for understanding business process reengineering. International Journal of Operations \& Production Management, 14(12), 22-34.

CHOUNTALAS, P. A. L., A.G. 2012. A Critical Review of Business Process Management Models., Volume of Essays in Honour of Prof. S. Karvounis. Available: https://ssrn.com/abstract=2632770 [Accessed May 31, 2012].

CLEMONS, E. K., THATCHER, M. E. \& ROW, M. C. 1995. Identifying sources of reengineering failures: A study of the behavioral factors contributing to reengineering risks. Journal of Management Information Systems, 12(2), 9-36.

COLICCHIA, C. \& STROZZI, F. 2012. Supply chain risk management: a new methodology for a systematic literature review. Supply Chain Management: An International Journal, 17(4), 403-418.

CURTIS, B., KELLNER, M. I. \& OVER, J. 1992. Process modeling. Communications of the ACM, 35(9), 75-90.

DADAM, P. 2008. The Future of BPM: Flying with the Eagles or Scratching with the Chickens? In International Conference on Business Process Management (pp. 3-3). Berlin Heidelberg: Springer.

DAVENPORT, T. H. \& STODDARD, D. B. 1994. Reengineering: business change of mythic proportions? MIS quarterly, 18(2), 121-127.

DE BRUIN, T. 2009. Theory on Progression and Maturity. Doctoral dissertation, Queensland University of Technology Brisbane.

DEL GIUDICE, M. 2016. Discovering the Internet of Things (IOT): technology and business process management, inside and outside the innovative firms. Business Process Management Journal, 22(2).

DESANCTIS, G. 2003. The social life of information systems research: A response to Benbasat and Zmud's call for returning to the IT artifact. Journal of the Association for Information Systems, 4(1), 16.

DI CICCIO, C., MARRELLA, A. \& RUSSO, A. 2015. Knowledge-intensive processes: characteristics, requirements and analysis of contemporary approaches. Journal on Data Semantics, 4(1), 29-57.

DIJKMAN, R., DUMAS, M. \& OUYANG, C. 2008. Semantics and analysis of business process models in BPMN. Information and Software Technology, 50(12), 1281-1294.

DIJKMAN, R., DUMAS, M., VAN DONGEN, B., KÄÄRIK, R. \& MENDLING, J. 2011. Similarity of business process models: Metrics and evaluation. Information Systems, 36(2), 498-516.

DONGEN, V. B., MEDEIROS, D. A., VERBEEK, H., WEIJTERS, A. \& VAN DER AALST, W. 2005. The PRoM framework: a new era in process mining tool support. Springer Berlin Heidelberg, 3536444454.

DUMAS, M., LA ROSA, M., MENDLING, J. \& REIJERS, H. A. 2013. Fundamentals of business process management, Heidelberg, Springer.

DUMAS, M., VAN DER AALST, W. \& TER HOFSTEDE, A. H. 2005. Process-aware information systems: bridging people and software through process technology, New York, John Wiley \& Sons.

ELZINGA, D. J., HORAK, T., LEE, C.-Y. \& BRUNER, C. 1995. Business process management: survey and methodology. Engineering Management, IEEE Transactions on, 42(2), 119-128.

EROL, S., GRANITZER, M., HAPP, S., JANTUNEN, S., JENNINGS, B., JOHANNESSON, P., KOSCHMIDER, A., NURCAN, S., ROSSI, D. \& SCHMIDT, R. 2010. Combining BPM and social software: contradiction or chance? Journal of software maintenance and evolution: research and practice, 22(6-7), 449-476. 
FINKELSTEIN, A., KRAMER, J. \& NUSEIBEH, B. 1994. Software process modelling and technology, New York, NY, John Wiley \& Sons, Inc.

FOWLER, M. 2001. The new methodology. Wuhan University Journal of Natural Sciences, 6(1), 12-24.

GALLIERS, R. D. 2003. Change as crisis or growth? Toward a trans-disciplinary view of information systems as a field of study: A response to Benbasat and Zmud's call for returning to the IT artifact. Journal of the Association for Information Systems, 4(1), 13.

GMÜR, M. 2003. Co-citation analysis and the search for invisible colleges: A methodological evaluation. Scientometrics, 57(1), 27-57.

GORBACHEVA, E., STEIN, A., SCHMIEDEL, T. \& MÜLLER, O. 2015. A Gender Perspective on Business Process Management Competences Offered on Professional Online Social Networks. ECIS. Muenster.

GROVER, V., GOKHALE, R., LIM, J., COFFEY, J. \& AYYAGARI, R. 2006. A citation analysis of the evolution and state of information systems within a constellation of reference disciplines. Journal of the Association for Information Systems, 7(5), 13.

HALL, E. A., ROSENTHAL, J. \& WADE, J. 1993. How to make reengineering really work. Harvard business review, 2(november-december), 107-129.

HALL, J. M. \& JOHNSON, M. E. 2009. When should a process be art, not science? Harvard business review, 87(3), 58-65.

HAMMER, M. 1990. Reengineering work: don't automate, obliterate. Harvard business review, 68(4), 104-112.

HAMMER, M. 2007. The process audit. Harvard Business Review, 85(4), 111-123.

HAMMER, M. \& CHAMPY, J. 1993. Reengineering the Corporation, New York, HaperCollins.

HARMON, P. 2010. The scope and evolution of business process management. Handbook on Business Process Management 1. Berlin Heidelberg: Springer.

HERROELEN, W. 2005. Project scheduling-Theory and practice. Production and operations management, 14(4), 413-432.

HEVNER, A. R., MARCH, S. T., PARK, J. \& RAM, S. 2004. Design science in information systems research. MIS quarterly, 28(1), 75-105.

HOMMES, B.-J. \& VAN REIJSWOUD, V. Assessing the quality of business process modelling techniques. System Sciences, 2000. Proceedings of the 33rd Annual Hawaii International Conference on, 2000. IEEE, $10 \mathrm{pp}$. vol. 1.

HOOD, W. W. \& WILSON, C. S. 2003. Informetric studies using databases: opportunities and challenges. Scientometrics (58), 587-608.

HUMMON, N. P. \& DEREIAN, P. 1989. Connectivity in a citation network: The development of DNA theory. Social Networks, 11(1), 39-63.

HUNG, R. Y.-Y. 2006. Business process management as competitive advantage: a review and empirical study. Total Quality Management \& Business Excellence, 17(1), 21-40.

IRITANI, D. R., MORIOKA, S. N., DE CARVALHO, M. M. \& OMETTO, A. R. 2015. Analysis of business process management theory and practices: systematic literature review and bibliometrics. Gestão \& Produção, 22(1), 164-180.

JESTON, J. \& NELIS, J. 2008. How to Demystify BPM? BPTrends [Online].

JOHANSSON, H. M., P., PENDLEBURY, A. J., \& WHEELER, W. A. 1993. Business process reengineering: Breakpoint strategies for market dominance, Chichester, John Wiley \& Sons.

KARIM, J., SOMERS, T. M. \& BHATTACHERJEE, A. 2007. The impact of ERP implementation on business process outcomes: A factor-based study. Journal of Management Information Systems, 24(1), 101-134. 
KETTINGER, W. J., TENG, J. T. C. \& GUHA, S. 1997. Business process change: A study of methodologies, techniques, and tools. MIS Quarterly, 21(1), 55-80.

KILUBI, I. 2016. Investigating current paradigms in supply chain risk management-a bibliometric study. Business Process Management Journal, 22(4), 662-692.

KOHLBACHER, M. 2010. The effects of process orientation: a literature review. Business Process Management Journal, 16(1), 135-152.

KROGSTIE, J., SINDRE, G. \& JØRGENSEN, H. 2006. Process models representing knowledge for action: a revised quality framework. European Journal of Information Systems, 15(1), 91-102.

LA ROSA, M., DUMAS, M., TER HOFSTEDE, A. H. \& MENDLING, J. 2011. Configurable multiperspective business process models. Information Systems, 36(2), 313-340.

LEE, R. G. \& DALE, B. G. 1998. Business process management: a review and evaluation. Business Process Management Journal, 4(3), 214-225.

LEYMANN, F. \& ALTENHUBER, W. 1994. Managing business processes as an information resource. IBM systems journal, 33(2), 326-348.

LEYMANN, F., ROLLER, D. \& SCHMIDT, M.-T. 2002. Web services and business process management. IBM systems Journal, 41(2), 198-211.

LIN, J., HO, C., SADIQ, W. \& ORLOWSKA, M. E. 2002. Using workflow technology to manage flexible elearning services. Educational Technology \& Society, 5(4), 116-123.

LINDLAND, O. I., SINDRE, G. \& SOLVBERG, A. 1994. Understanding quality in conceptual modeling. IEEE software, 11(2), 42-49.

LITTLE, J. D. 1970. Models and managers: The concept of a decision calculus. Management science, 16(8), B-466-B-485.

LYYTINEN, K. \& KING, J. L. 2004. Nothing at the center?: Academic legitimacy in the information systems field. Journal of the Association for Information Systems, 5(6), 8.

LYYTINEN, K. \& KING, J. L. 2006. Standard making: a critical research frontier for information systems research. Mis Quarterly, 30405-411.

MAJCHRZAK, A., MARKUS, M. L. \& WAREHAM, J. 2016. Designing for Digital Transformation: Lessons for Information Systems Research from the Study of ICT and Societal Challenges. MIS Quarterly, 40(2), 267-277.

MALIK, A., SINHA, A. \& BLUMENFELD, S. 2012. Role of quality management capabilities in developing market-based organisational learning capabilities: Case study evidence from four Indian business process outsourcing firms. Industrial Marketing Management, 41(4), 639-648.

MALONE, T. W., CROWSTON, K., LEE, J., PENTLAND, B., DELLAROCAS, C., WYNER, G., QUIMBY, J., OSBORN, C. S., BERNSTEIN, A. \& HERMAN, G. 1999. Tools for inventing organizations: Toward a handbook of organizational processes. Management Science, 45(3), 425-443.

MARINŠEK, D. 2015. A Review of Capital Structure Theory Using a Bibliometric Analysis. Metodološki zvezki 12(2), 69-84.

MCCAIN, K. W. 1990. Mapping authors in intellectual space: A technical overview. Journal of the American society for information science, 41(6), 433-443.

MCCOY, D., M.CANTARA. 2010. Hype Cycle for Business Process Management, 2010.

MELÃO, N. \& PIDD, M. 2000. A conceptual framework for understanding business processes and business process modelling. Information Systems Journal, 10(2), 105-129.

MELVILLE, N., KRAEMER, K. \& GURBAXANI, V. 2004. Review: Information technology and organizational performance: An integrative model of IT business value. MIS quarterly, 28(2), 283-322.

MENDLING, J. 2007. Detection and prediction of errors in EPC business process models. Doctoral degree, Wirtschaftsuniversität Wien Vienna. 
MENDLING, J. 2016. From Scientific Process Management to Process Science: Towards an empirical research agenda for Business Process Management. ZEUS 2016, 1.

MENDLING, J., REIJERS, H. A. \& RECKER, J. 2010a. Activity labeling in process modeling: Empirical insights and recommendations. Information Systems, 35(4), 467-482.

MENDLING, J., REIJERS, H. A. \& VAN DER AALST, W. 2010b. Seven process modeling guidelines (7PMG). Information and Software Technology, 52(2), 127-136.

MENDLING, J. \& STREMBECK, M. Influence factors of understanding business process models. International Conference on Business Information Systems, 2008. Springer Berlin Heidelberg, 142-153.

MENDLING, J., VERBEEK, H. M. W., VAN DONGEN, B. F., VAN DER AALST, W. \& NEUMANN, G. 2008. Detection and prediction of errors in EPCs of the SAP reference model,. Data \& Knowledge Engineering, 64(1), 312-329.

MEŠKO, I. \& MEŠKO, T. 1994. Fractional piecewise linear optimization of the business process including investments. Decision Support Systems, 12(3), 213-218.

MISHRA, D., LUO, Z., JIANG, S., PAPADOPOULOS, T. \& DUBEY, R. 2017. A bibliographic study on big data: concepts, trends and challenges. Business Process Management Journal, 23(3).

MØLLER, C., MAACK, C. J. \& TAN, R. D. 2007. What is business process management: A two stage literature review of an emerging field. Research and Practical Issues of Enterprise Information Systems II. Berlin Heidelberg: Springer.

MORENO-MONTES DE OCA, I., SNOECK, M., REIJERS, H. \& RODRÍGUEZ-MORFFI, A. 2015. A systematic literature review of studies on business process modeling quality. Information and Software Technology, 58187-205.

MURATA, T. 1989. Petri nets: Properties, analysis and applications. Proceedings of the IEEE, 77(4), 541-580.

NEWMAN, M. E. 2006. Modularity and community structure in networks. Proceedings of the national academy of sciences, 103(23), 8577-8582.

NEWMAN, M. E. \& GIRVAN, M. 2004. Finding and evaluating community structure in networks. Physical review $E, 69(2), 026113$.

OULD, M. A. 1997. Designing a re-engineering proof process architecture. Business Process Management Journal, 3(3), 232-247.

OZCELIK, Y. 2010. Do business process reengineering projects payoff? Evidence from the United States. International Journal of Project Management, 28(1), 7-13.

PALMER, N. 2011. What is BPM? BPM.com Enabling the Digital Enterprise [Online]. Available: Bpm. com/what-is-bpm [Accessed 9th May, 2016].

PASADEOS, Y., PHELPS, J. \& KIM, B.-H. 1998. Disciplinary impact of advertising scholars: temporal comparisons of influential authors, works and research networks. Journal of Advertising, 27(4), 53-70.

PASCALE, R. T. 1990. Managing on the Edge: How Successful Companies Use Conflict to Stay Ahead, New York, Simon and Schuster.

PENTLAND, B. T. 1999. Building process theory with narrative: From description to explanation. Academy of management Review, 24(4), 711-724.

PENTLAND, B. T. \& FELDMAN, M. S. 2005. Organizational routines as a unit of analysis. Industrial and corporate change, 14(5), 793-815.

PENTLAND, B. T. \& FELDMAN, M. S. 2008. Designing routines: On the folly of designing artifacts, while hoping for patterns of action. Information and Organization, 18(4), 235-250.

PENTLAND, B. T., FELDMAN, M. S., BECKER, M. C. \& LIU, P. 2012. Dynamics of organizational routines: A generative model. Journal of Management Studies, 49(8), 1484-1508. 
PENTLAND, B. T., H/EREM, T. \& HILLISON, D. 2010. Comparing organizational routines as recurrent patterns of action. Organization Studies, 31(7), 917-940.

PENTLAND, B. T. \& RUETER, H. H. 1994. Organizational routines as grammars of action. Administrative Science Quarterly, 484-510.

PERSSON, O., R. DANELL, J. WIBORG SCHNEIDER. 2009. How to use Bibexcel for various types of bibliometric analysis. In: F. ÅSTRÖM, R. D., B. LARSEN, J. SCHNEIDER, (ed.) In Celebrating scholarly communication studies: A Festschrift for Olle Persson at his 60th Birthday. Leuven, Belgium: International Society for Scientometrics and Informetrics. .

PESIC, M., SCHONENBERG, H. \& VAN DER AALST, W. Declare: Full support for loosely-structured processes. IEEE 11th International conference on Enterprise Distributed Object Computing, 2007. IEEE - Institute of Electrical and Electronics Engineers, 287-287.

PESIC, M. \& VAN DER AALST, W. A declarative approach for flexible business processes management. Business Process Management Workshops, 2006. Springer, 169-180.

PORTER, M. E. 1979. The Five Competitive Forces that Shape Strategy. Competitive strategy, MarchApril.

PORTER, M. E. \& MILLAR, V. E. 1985. How information gives you competitive advantage. 63(4), 149152.

RAMILLER, N., SWANSON, E. B. \& WANG, P. 2008. Research directions in information systems: Toward an institutional ecology. Journal of the Association for Information Systems, 9(1), 2.

RAMOS-RODRÍGUEZ, A. R. \& RUíZ-NAVARRO, J. 2004. Changes in the intellectual structure of strategic management research: A bibliometric study of the Strategic Management Journal, 1980-2000. Strategic Management Journal, 25(10), 981-1004.

RECKER, J. 2010. Continued use of process modeling grammars: the impact of individual difference factors. European Journal of Information Systems, 19(1), 76-92.

RECKER, J. 2014. Suggestions for the next wave of BPM research: strengthening the theoretical core and exploring the protective belt. JITTA: Journal of Information Technology Theory and Application, 15(2), 5.

RECKER, J. \& MENDLING, J. 2016. The state of the art of business process management research as published in the BPM conference. Business \& Information Systems Engineering, 58(1), 55-72.

REIJERS, H. A., MANS, R. \& VAN DER TOORN, R. A. 2009. Improved model management with aggregated business process models. Data \& Knowledge Engineering, 68(2), 221-243.

ROBEY, D. 2003. Identity, legitimacy and the dominant research paradigm: An alternative prescription for the IS discipline: A response to Benbasat and Zmud's call for returning to the IT artifact. Journal of the Association for Information Systems, 4(1), 15.

ROCKART, J. F. 1979. Critical success factors. Harvard Business Review, 57(2), 81-91.

ROSEMANN, M. 2006. Potential pitfalls of process modeling: part A. Business Process Management Journal, 12(2), 249-254.

ROSEMANN, M. 2014. Proposals for Future BPM Research Directions. In: CHUN OUYANG \& JUNG, J.Y. (eds.) Asia Pacific Business Process Management. Switzerland: Springer.

ROSEMANN, M. \& VOM BROCKE, J. 2015. The six core elements of business process management. Handbook on Business Process Management 1. Berlin Heidelberg: Springer.

ROSSI, M. \& BRINKKEMPER, S. 1996. Complexity metrics for systems development methods and techniques. Information Systems, 21(2), 209-227.

ROUSSEAU, D. M., MANNING, J. \& DENYER, D. 2008. Evidence in Management and Organizational Science: Assembling the Field's Full Weight of Scientific Knowledge Through Syntheses. The Academy of Management Annals, 2(1), 475-515. 
SADIQ, S. W., ORLOWSKA, M. E. \& SADIQ, W. 2005. Specification and validation of process constraints for flexible workflows. Information Systems, 30(5), 349-378.

SADIQ, S. W., SADIQ, W. \& ORLOWSKA, M. Pockets of flexibility in workflow specification. International Conference on Conceptual Modeling, 2001 Berlin Heidelberg. Springer, 513526.

SADIQ, W. \& ORLOWSKA, M. E. 2000. Analyzing process models using graph reduction techniques. Information Systems, 25(2), 117-134.

SCHEER, A.-W. \& NÜTTGENS, M. 2000. ARIS architecture and reference models for business process management, Berlin Heidelberg, Springer.

SCHILDT, H. A., ZAHRA, S. A. \& SILLANPÄÄ, A. 2006. Scholarly communities in entrepreneurship research: a co-citation analysis. Entrepreneurship Theory and Practice, 30(3), 399-415.

SCHMIEDEL, T., VOM BROCKE, J. \& RECKER, J. 2014. Development and validation of an instrument to measure organizational cultures' support of business process management. Information \& Management, 51(1), 43-56.

SHORT, J. E. \& VENKATRAMAN, N. 1992. Beyond business process redesign: redefining Baxter's business network. Sloan Management Review, 34(1), 7.

SIDOROVA, A. \& ISIK, O. 2010. Business process research: a cross-disciplinary review. Business Process Management Journal, 16(4), 566-597.

SILVA, A. R., MEZIANI, R., MAGALHAES, R., MARTINHO, D., AGUIAR, A. \& FLORES, N. AGILIPO: embedding social software features into business process tools. Business Process Management Workshops, 2010. Springer, 219-230.

SMALL, H. 1973. Co-citation in the scientific literature: a new measure of the relationship between two documents. Journal of the American Society for Information Science, 24265-269.

SMART, P., MADDERN, H. \& MAULL, R. 2009. Understanding Business Process Management: Implications for Theory and Practice. British Journal of Management, 20(4), 491-507.

TAYLOR 1911. The principles of scientific management, New York and London, Harper \& Brothers.

TAYLOR, H., DILLON, S. \& VAN WINGEN, M. 2010. Focus and diversity in information systems research: Meeting the dual demands of a healthy applied discipline. Mis Quarterly, 34(4), 647-667.

TENG, J. T., GROVER, V., \& FIEDLER, K. D. 1996. Developing strategic perspectives on business process reengineering: from process reconfiguration to organizational change. Omega, 24(3), 271-294.

TRAINOR, K. J., ANDZULIS, J. M., RAPP, A. \& AGNIHOTRI, R. 2014. Social media technology usage and customer relationship performance: A capabilities-based examination of social CRM. Journal of Business Research, 67(6), 1201-1208.

TRKMAN, P. 2010. The critical success factors of business process management. International Journal of Information Management, 30(2), 125-134.

TRKMAN, P. \& KLUN, M. 2015. Leveraging Social Media for Process Innovation. A Conceptual Framework. In: VOM BROCKE, J. \& SCHMIEDEL, T. (eds.) BPM: Driving Innovation in a Digital World. Switzerland: Springer International Publishing.

ÜSDIKEN, B. \& PASADEOS, Y. 1995. Organizational analysis in North America and Europe: A comparison of co-citation networks. Organization Studies, 16(3), 503-526.

VAN DER AALST, W. 1998. The application of Petri nets to workflow management. Journal of circuits, systems, and computers, 8(01), 21-66.

VAN DER AALST, W. 1999. Formalization and verification of event-driven process chains. Information and Software technology, 41(10), 639-650. 
VAN DER AALST, W. 2012. A decade of business process management conferences: personal reflections on a developing discipline. . In Business Process Management. Berlin Heidelberg: Springer

VAN DER AALST, W. 2013a. Business process management: A comprehensive survey. ISRN Software Engineering, 20131-37.

VAN DER AALST, W. 2013b. Business process management: a comprehensive survey. ISRN Software Engineering, 2013.

VAN DER AALST, W., BARROS, A. P., TER hOFSTEDE, A. H. \& KIEPUSZEWSKI, B. 2000. Advanced workflow patterns. In Cooperative Information Systems. Berlin Heidelberg: Springer

VAN DER AALST, W. \& SONG, M. 2004. Mining social networks: Uncovering interaction patterns in business processes. In: DESEL, J., PERNICl, B. \& WESKE, M. (eds.) Business Process Management. Berlin Heidelberg: Springer.

VAN DER AALST, W., TER HOFSTEDE, A. H. M. \& WESKE, M. 2003. Business process management: A survey. In: AALST, W. V. D., TERHOFSTEDE, A. \& WESKE, M. (eds.) Business Process Management, Proceedings. Berlin: Springer-Verlag Berlin.

VAN DER LINDEN, D. \& HADAR, I. Evaluating the Evaluators - An Analysis of Cognitive Effectiveness Improvement Efforts for Visual Notations. ENASE 2016 Proceedings of the 11th International Conference on Evaluation of Novel Software Approaches to Software Engineering, 2016 Rome, Italy.

VAN HEE, K. \& VAN DER AALST, W. 2002. Workflow Management: Models, Methods, ans Systems. Cambridge, Massachusetts: MIT Press Cambridge.

VENKATRAMAN, N. \& RAMANUJAM, V. 1986. Measurement of business performance in strategy research: A comparison of approaches. Academy of management review, 11(4), 801-814.

VERGIDIS, K., TURNER, C. J. \& TIWARI, A. 2008. Business process perspectives: Theoretical developments vs. real-world practice. International Journal of Production Economics, 114(1), 91-104.

VIDALES, M. A. S., GARCÍA, A. M. \& AGUILAR, L. J. 2008. A new MDA approach based on BPM and SOA to improve software development process. Tékhne-Revista de Estudos Politécnicos, (9), 70-90.

VOM BROCKE, J. Keynotes - 10 Principles of Good Business Process Management EMISA - 7th International Workshop on Enterprise Modeling and Information Systems Architectures, 2016 Vienna, Austria.

VOM BROCKE, J., BECKER, J., BRACCINI, A. M., BUTLERIS, R., HOFREITER, B., KAPOČIUS, K., DE MARCO, M., SCHMIDT, G., SEIDEL, S. \& SIMONS, A. 2011. Current and future issues in BPM research: a European perspective from the ERCIS meeting 2010. Communications of the Association for Information Systems, 28(1), 393-414.

VOM BROCKE, J. \& ROSEMANN, M. 2010. Handbook on business process management, Berlin Heidelberg, Springer.

VOM BROCKE, J. \& SINNL, T. 2011. Culture in business process management: a literature review. Business Process Management Journal, 17(2), 357-378.

VOM BROCKE, J., ZELT, S. \& SCHMIEDEL, T. 2015. On the role of context in business process management. International Journal of Information Management, 36(3), 486-495.

WEBER, B., REICHERT, M. \& RINDERLE-MA, S. 2008. Change patterns and change support featuresenhancing flexibility in process-aware information systems. Data \& knowledge engineering, 66(3), 438-466. 
WEIDLICH, M., MENDLING, J. \& WESKE, M. 2011. Efficient consistency measurement based on behavioral profiles of process models. Software Engineering, IEEE Transactions on, 37(3), 410-429.

WESKE, M. 2007. Business Process Management: Concepts, Methods, Technology, Berlin Heidelberg, Springer.

WHITE, H. D. \& GRIFFITH, B. C. 1981. Author cocitation: A literature measure of intellectual structure. Journal of the American Society for information Science, 32(3), 163-171.

YU, E. S. \& MYLOPOULOS, J. Understanding" why" in software process modelling, analysis, and design. Software Engineering, 1994. Proceedings. ICSE-16., 16th International Conference on, 1994. IEEE, 159-168.

ZAIRI, M. 1997. Business process management: a boundaryless approach to modern competitiveness. Business Process Management Journal, 3(1), 64-80.

ŽUPIČ, I. \& ČATER, T. 2015. Bibliometric methods in management and organization. Organizational research methods, 18(3), 429-472. 